\title{
Financial and economic analyses of conventional and new technology harvesting systems
}

\begin{abstract}
This paper examine the various committed new technology and improve logging activities ascribed in the 'Logfisher' Practice (LP) rather than Conventional Practice (CP). The result of cost analysis shows that the cost constitutes under LP is higher than under CP. Incremental average per ha total cost rose by $46.86 \%$ to RM13,576/ha. While the incremental average per m3 total cost increased by $57.41 \%$ to RM267.80/m3. Hence, CP was slightly more profitable and exceeds the Net Present Value (NPV) of LP. Similarly, the Benefit-Cost Ration (BCR) for CP is better than LP. On the other hand, the result of the economic analysis of 40-year period showed that the LP system (NPV = RM9302/ha) provided a higher level of overalls benefits and welfare to the society as a whole as opposed to CP (NPV = RM8497/ha).
\end{abstract}

Keyword: 'Logfisher' Practice (LP); Conventional Practice (CP); Logfisher; Net Present Value (NPV) 